\title{
JORNALISMO E DIREITOS HUMANOS: O AGENDAMENTO DO TEMA ESTUPRO NO PORTAL CAMPO GRANDE NEWS (MS)
}

\section{JOURNALISM AND HUMAN RIGHTS: THE SCHEDULING OF THE RAPE THEME IN CAMPO GRANDE NEWS (MS)}

\author{
Katarini Giroldo Miguel ${ }^{1}$ \\ Lynara Ojeda Souza²
}

\begin{abstract}
RESUMO: O presente artigo discute o papel dos meios de comunicaçăo na abordagem dos Direitos Humanos, especificamente na cobertura do tema estupro, e a influência da mobilizaçâo social nesse processo, sinalizando para as possíveis alteraçôes que ocorrem no agendamento dos temas quando no ciberespaço. Em um segundo momento, analisamos como o portal de notícias sul-mato-grossense Campo Grande News agendou o tema violência sexual de gênero, a partir da repercussăo nacional do caso de estupro coletivo de uma jovem no Rio de Janeiro em maio de 2016. Levantamos as matérias veiculadas nos 15 dias antes e depois do caso, para entender a composiçâo da pauta e indicar características e fluxos de agendamentos. Os resultados apontam para recorrência do assunto, forte influência das redes sociais digitais tanto na pauta quanto na abordagem; negligência de dados informativos que possam contextualizar a problemática e evidenciar sua gravidade no Estado: Mato Grosso do Sul ocupa o segundo lugar na lista de estados brasileiros com maior número de denúncias de estupro (SECRETARIA ESPECIAL DE POLÍTICAS PARA AS MULHERES, 2015).
\end{abstract}

PALAVRAS-CHAVE: Agendamento. Jornalismo. Estupro. Direitos Humanos.

ABSTRACT: This article investigates the role of the media in the approach to Human Rights, and the influence in society and social mobilization in this process, signaling to the possible changes that occur in the scheduling of themes when in cyberspace. In a second moment, we analyzed how the website Campo Grande News scheduled the theme sexual violence of gender, from the national repercussion of the case of collective rape of a young person in Rio de Janeiro in May of 2016. We selected the material published in the 15 days before and after the case, from May 10 to June

1 Jornalista, doutora em Comunicaçâo Social pela Universidade Metodista de S.Paulo. Docente no curso de Jornalismo e no Programa de Mestrado em Comunicaçáo da UFMS. katarini.miguel@ufms.br

2 Jornalista, mestre em Comunicaçáo pela Universidade Federal de Mato Grosso do Sul. lynaraojeda@gmail.com 
10, 2016, to understand the composition of the agenda and indicate characteristics and scheduling flows. The results shows the recurrence of the subject, influence of digital social networks in the schedule and the approach; lack of information that contextualize the problem and evidence its seriousness in the State: Mato Grosso do Sul occupies the second place in the list of Brazilian states with the highest number of reports of rape (SPECIAL SECRETARIAT OF POLICIES FOR WOMEN, 2015).

KEYWORDS: Agenda-Setting. Cyberjournalism. Rape. Human Rights.

\section{INTRODUÇÃO: JORNALISMO E DIREITOS HUMANOS}

É fato que os meios de comunicaçăo sâo determinantes para o desenvolvimento de uma sociedade e exercem forte influência nas pautas sociais, levando às pessoas as informaçōes para que possam compor suas opiniōes. Quando se refere a Direitos Humanos, os veículos de comunicaçăo săo considerados estratégicos e fundamentais para a fiscalizaçăo, promoçâo e divulgaçăo desses preceitos; permitem tomar conhecimento de serviços de relevância pública ou de direitos que precisam ser acessados e/ ou demandados.

Assim, o trabalho jornalístico é capaz de visibilizar diferentes temáticas para ofertar possibilidades para um debate crítico e pautado nas complexidades sociais que envolvem as mudanças de paradigmas nos direitos fundamentais. Uma prática jornalística dedicada à contextualizaçâo das notícias fortalece a cidadania e auxilia a revigorar e ampliar o capital social.

Desde o advento da Declaraçáo Universal dos Direitos do Homem de 1948 e reiteraçăo na Declaraçăo de Direitos Humanos de Viena de 1993, a sociedade tem se organizado de modo a tentar compreender essa concepçâo como um conjunto mínimo de direitos que cada ser humano possui baseado no respeito e garantia de sua dignidade. É daí que decorre a importância dos Direitos Humanos no mundo contemporâneo, bem como a incorporaçấo do tema nos discursos e atividades por parte de diversos segmentos da sociedade: governos, instituiçôes internacionais, movimentos sociais e mídia.

No Brasil, o marco na democratizaçăo foi a Constituiçăo Federal de 1988, "colocando-se entre as Constituiçóes mais avançadas do mundo" (PIOVESAN, 2007, p. 25), e que garantiu, em seu ordenamento jurídico, os direitos fundamentais estabelecidos pelos documentos internacionais dos quais o país é signatário.

A promoçáo e a discussăo acerca dos Direitos Humanos mostram-se como um grande desafio para os jornalistas, que săo atores importantes e estratégicos para a garantia de direitos e possuem funçăo singular quando apresentam uma abordagem qualificada e problematizadora sobre o tema.

Segundo Vidigal (2002, p. 1), "a reportagem se contenta apenas com a cobertura, ou seja, com a descriçấo pura e simples do evento e as aspas nas bocas de algumas personagens". Os valores mercadológicos têm atropelado os valores éticos e essenciais da profissáo, o que, na maior parte das vezes, transforma a notícia em espetáculo, sem conteúdos realmente relevantes e, assim, o público é reconhecido apenas com uma única característica, o de consumidor. 
Nossa preocupaçấo é como os profissionais do jornalismo compreendem os temas e os reproduzem e, com isso, se há uma apropriaçăo ou nâo da complexidade e das especificidades que envolvem a abordagem de violaçôes de direitos. Uma pesquisa realizada pela $\operatorname{ANDI}^{3}$ ([s/d]), indica que a imprensa brasileira năo aponta diretamente os Direitos Humanos como sendo os responsáveis pelos elevados índices de violência no país. Somente $0,3 \%$ dos textos pesquisados investiram nessa abordagem. Nesse contexto surge um questionamento: será que a cobertura dos jornais pode contribuir para uma percepçáo distorcida da questăo? Conforme a pesquisa realizada pela ANDI, em 25\% das reportagens analisadas, o tema Direitos Humanos está associado à segurança e à violência.

Enquanto isto, assuntos como pobreza e educaçăo alcançam índices dez vezes menores, conforme mencionado anteriormente. É por meio de desequilíbrios tăo marcantes em suas pautas que a mídia acaba contribuindo para reforçar no imaginário popular a idéia de que Direitos Humanos săo de interesse apenas para quem está envolvido em atos delituosos (ANDI, [s.d], p. 6).

As notícias săo resultado de um processo negociado, no qual os jornalistas năo sâo simplesmente observadores passivos, mas participantes ativos na projeçáo da realidade. Para Sodré (2009, p. 26), "jornalismo năo é reflexo, mas construçăo social de uma realidade específica. Da cultura profissional dos jornalistas, da organizaçăo geral do trabalho e dos processos produtivos". Contudo, reconhecemos que abordar temas relacionados aos Direitos Humanos pode ser um desafio, uma vez que exige entendimento sobre os marcos legislativos e conceituais adotados pelo Estado brasileiro. Além disso, as próprias rotinas de produçăo comprometem a consistência das pautas.

Este artigo tem como propósito justamente levantar discussôes acerca do papel desempenhado pelos meios de comunicaçâo na cobertura de um tema do âmbito dos Direitos Humanos, especificamente na temática da violência contra a mulher. Para isso, recorremos à hipótese da agenda-setting/teoria do agendamento com a proposta de problematizar a produçăo da notícia - na cobertura de um dos crimes mais urgentes na atualidade quando se trata de violaçâo de direitos, que é o estupro -, seu potencial de influenciar e ser influenciado por diferentes fluxos informativos do ciberespaço.

O agendamento parte do pressuposto que a mídia é capaz de pautar a sociedade. Avaliando desta forma, os meios de comunicaçâo teriam uma participaçăo direta sobre as opiniôes das pessoas, e, essencialmente, a agenda-setting procura identificar se os temas que sâo expostos na grande mídia se tornam importantes para o público, assim como se sâo pauta das preocupaçôes cotidianas. Mas o fluxo contrário também é possível, e a sociedade exerce influência nas pautas midiáticas. O ciberespaço e as possibilidades de difundir e democratizar a informaçáo facilitam o processo de muitos para muitos e a agenda pode se desconstruída. Nosso corpus abrange a cobertura do caso de estupro coletivo, ocorrido no Rio de Janeiro em maio de 2016, e como o fato, pautado exaustivamente por veículos convencionais nacionais e cibermeios,

3 É uma organizaçăo da sociedade civil, sem fins de lucro e apartidária, que articula açôes inovadoras em mídia para o desenvolvimento. Suas estratégias estáo fundamentadas na promoçăo e no fortalecimento de um diálogo profissional e ético entre as redaçōes, as faculdades de comunicaçấo e de outros campos do conhecimento, os poderes públicos e as entidades relacionadas à agenda do desenvolvimento sustentável e dos direitos humanos nos âmbitos nacional e global. 
repercutiu em âmbito local. Realizamos, entăo, uma pesquisa exploratória, de cunho quanti-qualitativo no portal Campo Grande News, verificando ao longo de 30 dias a quantidade de notícias publicadas e suas abordagens, na tentativa de sinalizar de que maneira o debate público vem se constituindo a esse respeito, uma vez que a mídia atua nessa mediaçáo, e se o próprio portal informativo (aqui colocado como ciberjornal) foi agendado por outros veículos ou redes sociais digitais.

Para a análise, elaboramos uma tabela com informaçōes sobre a data, gênero jornalístico, título, contextualizaçăo local, origem da produçâo e princípios éticos normativos, que permitiu inferências importantes. No total, identificamos nove textos, publicados predominantemente nos dois dias após o crime, no ímpeto do acontecimento, o que acusa uma cobertura episódica, e agendada pelas redes sociais, como averiguamos já pelos títulos e fontes de informaçăo, configurando agendamento e contra-agendamento. Além disso, os textos têm uma característica bastante opinativa, condenam o crime, problematizam a cultura do estupro, mas nâo referenciam a legislaçáo vigente.

\section{AGENDAMENTO: HIPÓTESES E TRANSFORMAÇÕES EM UMA COBERTURA ANUNCIADA}

Dentro dos estudos sobre os efeitos dos meios de comunicaçâo na sociedade, está a hipótese da Agenda-Setting nos anos 1970, a partir de pesquisas realizadas por Maxwell McCombs e Donald Shaw com o objetivo de analisar a influência da mídia na decisăo dos eleitores durante a campanha presidencial dos Estados Unidos, em 1968. Por meio desses estudos, dimensionou-se a capacidade do jornalismo exercer influência na opiniăo pública. Como Barros Filho define (2001, p. 169), "é a hipótese segundo a qual a mídia, pela seleçăo, disposiçăo e incidência de suas notícias, vem determinar os temas sobre os quais o público falará e discutirá".

Embora a agenda-setting tenha sido sistematizada por McCombs e Shaw outros pesquisadores estudaram a atençáo que o público dirigia para os temas propostos pela imprensa. Em 1922, Walter Lippmann, em Opiniâo Pública, dedicou-se a investigar o papel da imprensa no enquadramento da atençăo dos leitores em direçấo a temas por ela impostos como "de interesse coletivo". Lippmann (2010) fez mençáo ao modo como as pessoas chegam a conhecer o mundo exterior e sua própria existência, como formam as imagens em suas mentes. Os meios de difusăo modelam essas imagens ao selecionar e organizar símbolos de um mundo real.

Para Barros Filho (2001) foi em um artigo escrito por Norton Long em 1958 que a hipótese do agendamento temático foi claramente emitida: "o jornal é o primeiro motor da fixaçăo da agenda territorial. Ele tem grande participaçăo na definiçấo do que as pessoas conversarăo, o que as pessoas pensarâo que sâo os fatos e como se deve lidar com os problemas" (LONG, 1958 apud BARROS FILHO, 2001, p. 175).

O conceito mais sucinto que antecedeu o primeiro estudo empírico do agenda-setting foi construído por Cohen, em 1963, "embora a imprensa, na maior parte das vezes, possa năo ser bem sucedida ao indicar às pessoas como pensar, é espantosamente eficaz ao dizer aos seus leitores sobre o que pensar" (MCCOMBS; SHAW, 1972 apud TRAQUINA, 2000, p. 49). 
Já Traquina (2000) pondera que a problemática do efeito do agendamento seja diferente de acordo com a natureza da questâo e dos meios. A influência da agenda pública sobre a agenda da mídia é um processo gradual através do qual, em longo prazo, criam-se critérios de noticiabilidade ${ }^{4}$ enquanto a influência da agenda da mídia sobre a agenda pública é direta e imediata, principalmente quando envolve questóes que o público năo tem uma experiência direta. Isso porque, além do acesso aos meios de comunicaçấo e às conversas interpessoais, as pessoas precisam de diretrizes para entendimento de certos temas.

Uma junçăo de duas variáveis: alto interesse e um alto nível de incerteza. Assim, o efeito de agendamento ocorre com pessoas que têm uma grande necessidade de obter informaçăo sobre um assunto; devido a esta 'necessidade de orientaçăo', estas pessoas expóem-se mais aos media noticiosos, provocando maiores efeitos de agendamento (MCCOMBS; WEAVER; SPELLMAN, 1975 apud TRAQUINA, 2000, p. 33-34).

Traquina (2000) destaca a perspectiva de Mccombs; Weaver; Spellman sobre o impacto da funçâo do agendamento depender do repertório da recepçâo: os meios de comunicaçâo social podem mais do que reforçar opiniôes existentes, chegam a direcionar a atençăo para questóes e tópicos específicos.

Os estudos sinalizavam, portanto, para o papel da imprensa enquanto "estruturadora" de percepçóes e cogniçóes a respeito dos acontecimentos da realidade social, funçấo que ainda exerce nos dias de hoje e foi potencializada pelas TICs (Tecnologias da Informaçăo e Comunicaçăo).

Principalmente com o advento da internet, surgem também novas formas de agendamento e valores-notícia para o jornalismo, e o escopo do ciberjornalismo. Para Padilha (2012), no tal ciberjornalismo existe um crescimento dos espaços, e assim tudo parece ser noticiável. Tal característica faz com que as estratégias de agendamento mudem, uma vez que:

O conteúdo noticioso publicado na internet tem dinâmica muito peculiar. Dinâmica que, historicamente, colocou em xeque alguns preceitos de publicaçáo da notícia, como os relacionados à atualizaçăo, ao direcionamento da leitura, ao arquivamento e à pesquisa (PADILHA, 2012, p. 207).

Para cidadăos e jornalistas, a avalanche de informaçôes e o acesso a diversas formas de produzir e difundir notícias provocam diferentes impactos e a própria desconstruçâo da lógica da agenda-setting. Sites de redes sociais, ferramentas de participaçăo, produçăo colaborativa de informaçóes disponibilizadas pela Internet dăo voz a diferentes grupos, que ganham protagonismo e indicam a constituiçăo de novos fluxos de agendamento, que buscamos problematizar no presente trabalho.

A discussâo que os movimentos sociais, por exemplo, fazem acerca da influência dos meios de comunicaçăo na pauta pública pode ser ancorada na hipótese do agendamento.

4 Para Gislene Silva (2005, p. 96) os critérios de noticiabilidade podem ser definidos como "todo e qualquer fator potencialmente capaz de agir no processo de produçáo da notícia, desde características do fato, julgamentos pessoais do jornalista, cultura profissional da categoria, condiçôes favorecedoras ou limitantes da empresa de mídia, qualidade do material [...], relaçâo com as fontes e com o público, fatores éticos e ainda circunstâncias históricas, políticas, econômicas e sociais". 
Há o reconhecimento, por parte deles, da capacidade dos meios de comunicaçăo de intervir em assuntos de interesse dos diferentes grupos sociais e das esferas do poder.

O jornalismo, dessa maneira, teria um significativo impacto nos processos políticos de deliberaçăo e decisáo, ajudando a definir quais questôes săo reconhecidas como problemas sociais, quem săo os responsáveis por eles e o que deveria ser feito para solucioná-los (ANDI, 2006, p. 15-16).

A influência ditada pela hipótese do agendamento confirma a necessidade de pautar temas nos meios de comunicaçăo para pautar a sociedade. Observamos, entăo, que movimentos e instituiçôes que atuam na proteçấo e garantia dos Direitos Humanos, atualmente, reconhecendo a ainda centralidade e poder da mídia, exercem um papel estratégico no agendamento de temas ligados à cidadania, seguindo uma dinâmica que denominamos de contra-agendamento. Explicamos.

De acordo com Mora (2008, p.26), esse agendamento da sociedade para mídia náo seria excludente ao movimento tradicional proposto pela teoria do agenda-setting, e sim complementar.

Para trabalhar a hipótese de que o agendamento de contra-fluxo é possível e de que esse contra-agendamento atua de forma complementar ao fluxo da mídia para a sociedade, vindo a ser denominado, portanto, de co-agendamento, operam-se três conceitos [...]: mediaçáo, agendamento e advocacy.

Assim, a sociedade, organizada ou nâo, se mobiliza de modo a sensibilizar e pautar os meios de comunicaçâo sobre assuntos que consideram de relevância social, a fim de fomentar a produçâo da notícia de utilidade pública e estabelecer uma parceria com os profissionais da imprensa. Silva (2010) apud Lago e Benetti (2010, p. 85) afirma que, "pode-se, entăo, afirmar que o contra-agendamento de um tema pode ser parte de uma mobilizaçăo social; parte de um plano de enfrentamento de um problema, corporativo ou coletivo". O mesmo autor (2010) salienta ainda que, ao analisar esse contra-agendamento, é preciso diferenciar as açōes fruto de mobilizaçóes sociais que resultam em notícias, de trabalhos elaborados por assessorias de imprensa e lobbies que pretendem emplacar seus assuntos ou produtos, pois pode resultar, muitas vezes, em dividendos privados e náo coletivos.

Desse modo, observamos que, na temática da violência sexual contra a mulher, a sociedade tem se apropriado das TICs na tentativa de dar visibilidade ao problema, mas também para ancorar a imprensa e, assim, alcançar diversas frentes e ampliar o debate público. Notamos e discutimos essas influências a partir da produçăo noticiosa no ciberespaço propriamente, com base em uma cobertura específica de um portal de Mato Grosso do Sul, nos atentando, nesse primeiro momento e na limitaçáo de um artigo, para a quantidade, qualidade dos textos e indícios do contra-agendamento.

\section{O MAPA DA VIOLÊNCIA CONTRA A MULHER E SUA NOTICIABILIDADE EM MS}

Dados do Mapa da Violência de 2015, levantados pelo Ministério da Saúde entre 1980 e 2013, indicam que o país contabilizou 106.093 assassinatos de mulheres, o que o deixa em $5^{\circ}$ lugar entre 83 países pesquisados. Os assassinatos atingem 66,7\% mais 
meninas e mulheres negras do que brancas. Campo Grande (MS) apresenta o maior número de denúncias de violência contra as mulheres no Brasil. Segundo dados da Central de Atendimento à Mulher, levantados pela Secretaria Especial de Políticas para as Mulheres (SEPM), em 2015, Campo Grande foi a capital brasileira com a maior taxa de relatos de violência. De 227,53 relatos por cada 100 mil mulheres, seguida por Rio de Janeiro, de 119,09, e Natal, de 113,43. A maioria dos relatos recebidos pela Central de Atendimento é de violência física, com 50,15\% dos casos, e violência psicológica, 30,33\%.

Uma das categorias de violência com números mais expressivos quando falamos de mulheres é o estupro. Em 2016, 49 mil pessoas foram vítimas de violência sexual no Brasil. Ou seja, a cada 11 minutos, uma mulher foi violentada no país. Os índices, que săo do $11^{\circ}$ Anuário Brasileiro de Segurança Pública (2017), consideram somente os casos que foram registrados em boletins de ocorrência. Contudo, segundo a publicaçăo, apenas $10 \%$ das vítimas desse tipo de crime costumam prestar queixas à polícia, de acordo com estimativa do Instituto de Pesquisa Econômica Aplicada (IPEA). De acordo ainda com o relatório, Mato Grosso do Sul liderou o ranking dos estados brasileiros com a maior taxa percentual, totalizando 54,4 estupros para cada 100 mil habitantes. Em 2016, foram registrados no Estado 1.458 crimes de estupros. O Estado do Amapá ocupou o segundo lugar, registrando 385 casos totalizando uma taxa de 49,2 por 100 mil habitantes. Já o Estado do Espírito Santo ocupou a última posiçâo com 188 casos de estupros registrados, totalizando um percentual de 4,7 a cada 100 mil habitantes.

Em 25 de maio de 2016, após uma série de denúncias contra um vídeo, que circulava nas redes sociais com imagens de um estupro coletivo de uma jovem, no Rio de Janeiro, cometido por cerca de 30 homens, os jornais de âmbito nacional divulgaram as primeiras informaçôes sobre o caso (identificamos a primeira publicaçăo no portal G1 no próprio dia 255). Grupos independentes e organizados se manifestaram prontamente iniciando uma mobilizaçáo que ganhou protagonismo nas redes sociais e repercussáo direta nos meios de comunicaçăo, exigindo ir além da notícia. A hashtags (frases e palavras-chave destacadas que etiquetam o assunto e facilitam a busca na Internet) \# estupronaoéculpadavitima \#eulutocontraofimdaculturadoestupro \#estupronuncamais ganharam projeçăo internacional; debates e mobilizaçóes contra a cultura do estupro foram organizados por todo o país. Com o intuito de entender a reverberaçâo local do caso, a partir do agendamento do ciberjornalismo e do tratamento dado à temática, vinculada aos Direitos Humanos, recorremos a uma avaliaçăo exploratória do portal Campo Grande News, que apresentamos na sequência.

O Campo Grande News ${ }^{6}$, fundado em março de 1999 e que atualmente é o ciberjonal mais acessado do Mato Grosso do Sul, com média de dois milhóes de visitas mensais ${ }^{7}$, publicou pela primeira vez sobre o crime no dia 26 de maio. Analisamos as publicaçôes sobre violência sexual num período que compreende 15 dias antes do caso aparecer nos jornais de circulaçáo nacional e 15 dias depois, portanto, de 10 de maio a 10 de junho de 2016.

5 Disponível em: http://g1.globo.com/rio-de-janeiro/noticia/2016/05/policia-do-rio-apura-supostoestupro-coletivo-e-identifica-autores-de-posts.html. Acesso em 09 nov.2018

6 Disponível em: www.campograndenews.com.br. Acesso em 10 jun.2018

7 Dados do site https://www.similarweb.com. Acesso em 08 jun.2018. 
Para coletar as publicaçóes, utilizamos a ferramenta de busca oferecida pelo portal Campo Grande News; limitadas entre as datas propostas, com a utilizaçáo das palavras-chaves: estupro, estupro coletivo, violência sexual contra mulher. Foram contabilizadas, no período, nove publicaçōes entre notas, notícias, reportagens, artigos e crônicas ${ }^{8}$; sendo a primeira no dia 26 de maio, quatro delas no dia 27, duas em 28 de maio e as outras duas respectivamente nos dias 30 e 31 de maio. Sete textos eram de produçăo local (sendo duas notícias, três opinativos, uma nota e uma caracterizada como reportagem, mas que problematizamos mais a frente) e duas reproduçóes da Agência Brasil.

Para verificarmos a dinâmica do agendamento do tema no jornal, no quesito quantidade e conteúdo, elaboramos a 'Tabela 1. Levantamento dos Textos do Campo Grande News', elencando data de publicaçâo, gênero/formato jornalístico, título, relaçâo do texto com o contexto local, origem da produçăo e princípios éticos e normativos relativos aos direitos humanos, considerando as legislaçóes vigentes de violência contra a mulher, o crime de estupro e o Estatuto da Criança e do Adolescente (Lei $n^{\circ}$ 8.069/1990), uma vez que a vítima envolvida no caso era uma adolescente.

Tabela. Levantamento dos textos do Campo Grande News

\begin{tabular}{|c|c|c|c|c|c|}
\hline Data & Gênero/formato & Título & Produção & $\begin{array}{c}\text { Contexto } \\
\text { local }\end{array}$ & Princípios éticos e normativos \\
\hline $26 / 05$ & $\begin{array}{l}\text { Reportagem/ } \\
\text { Interpretativo }\end{array}$ & $\begin{array}{l}\text { Em crimes que } \\
\text { envolvem estu- } \\
\text { pro, precisamos } \\
\text { expor o pro- } \\
\text { blema e náo a } \\
\text { vítima }\end{array}$ & CG News & Sim & $\begin{array}{l}\text { Uso adequado de terminologias; } \\
\text { contextualizaçâo conceitual sobre } \\
\text { relaçóes de gênero e poder, ma- } \\
\text { chismo e cultura do estupro; usa } \\
\text { fontes locais para falar sobre a } \\
\text { mobilizaçâo no Estado. }\end{array}$ \\
\hline $27 / 05$ & $\begin{array}{l}\text { Artigo/ } \\
\text { Opinativo }\end{array}$ & $\begin{array}{l}\text { Contra a cultura } \\
\text { do estupro e o } \\
\text { medo diário, de- } \\
\text { sejamos homens } \\
\text { melhores }\end{array}$ & CG News & Năo & $\begin{array}{l}\text { Uso adequado de terminologias; } \\
\text { contextualizaçáo conceitual sobre } \\
\text { relaçôes de gênero e poder, ma- } \\
\text { chismo e cultura do estupro, apro- } \\
\text { xima a vítima de outras mulheres. }\end{array}$ \\
\hline $27 / 05$ & $\begin{array}{l}\text { Noticia/ } \\
\text { Informativo }\end{array}$ & $\begin{array}{l}\text { OAB classifica } \\
\text { como } \\
\text { "inaceitável" } \\
\text { e divulga nota } \\
\text { em repúdio a } \\
\text { estupro coletivo }\end{array}$ & CG News & Năo & $\begin{array}{l}\text { Uso adequado de terminologias; } \\
\text { contextualizaçáo conceitual sobre } \\
\text { relaçôes de gênero e poder, ma- } \\
\text { chismo; cita políticas públicas para } \\
\text { promoçâo dos Direitos Humanos e } \\
\text { enfrentamento à violência sexual. }\end{array}$ \\
\hline $27 / 05$ & $\begin{array}{l}\text { Notícia/ } \\
\text { Informativo }\end{array}$ & $\begin{array}{l}\text { Temer anuncia } \\
\text { departamento } \\
\text { naPF para } \\
\text { combater } \\
\text { crimes contra } \\
\text { mulher }\end{array}$ & $\begin{array}{l}\text { Agência } \\
\text { Brasil }\end{array}$ & Nâo & $\begin{array}{l}\text { Uso adequado de terminologias; re- } \\
\text { laçáo com outros casos de estupro; } \\
\text { abordagem da responsabilizaçăo } \\
\text { feita pela justiça; uso de comuni- } \\
\text { cado da ONU Mulher para falar do } \\
\text { caso na perspectiva da proteçăo } \\
\text { aos Direitos Humanos. }\end{array}$ \\
\hline
\end{tabular}

8 Adotamos aqui o entendimento de Melo (1994) que coloca a nota, notícia e reportagem como formatos do gênero informativo (factual), e a caracterizaçáo depende da extensáo do texto e do seu nível de profundidade; sendo a reportagem a mais complexa e que pode ser alocada também no âmbito interpretativo. Já artigo e crônica săo do gênero opinativo, trazem exposiçâo direta das ideias de um autor, que năo necessariamente precisa ser um jornalista. 


\begin{tabular}{|c|c|c|c|c|c|}
\hline Data & Gênero/formato & Título & Produçăo & $\begin{array}{l}\text { Contexto } \\
\text { local }\end{array}$ & Princípios éticos e normativos \\
\hline $27 / 05$ & $\begin{array}{l}\text { Notícia/ } \\
\text { Informativo }\end{array}$ & $\begin{array}{l}\text { Líder feminina } \\
\text { no Congresso, } \\
\text { Simone se diz } \\
\text { chocada com } \\
\text { estupro coletivo } \\
\text { no RJ }\end{array}$ & CG News & Năo & $\begin{array}{l}\text { Uso adequado de terminologias e } \\
\text { citaçăo de Projeto de Lei sobre o } \\
\text { tema }\end{array}$ \\
\hline $28 / 05$ & $\begin{array}{c}\text { Nota/ } \\
\text { Informativo }\end{array}$ & $\begin{array}{l}\text { Nada revoltou } \\
\text { mais que o estu- } \\
\text { pro coletivo e o } \\
\text { machismo nesta } \\
\text { semana }\end{array}$ & CG News & Năo & Năo houve referência. \\
\hline $28 / 05$ & $\begin{array}{l}\text { Artigo/ } \\
\text { Opinativo }\end{array}$ & $\begin{array}{l}\text { Uma história na- } \\
\text { tural do estupro }\end{array}$ & CG News & Năo & $\begin{array}{l}\text { Uso adequado de terminologias; } \\
\text { contextualizaçăo conceitual } \\
\text { sobre relaçóes de gênero e poder, } \\
\text { machismo e cultura do estupro. }\end{array}$ \\
\hline $30 / 05$ & $\begin{array}{l}\text { Crônica/ } \\
\text { Opinativo }\end{array}$ & $\begin{array}{l}\text { No tribunal das } \\
\text { redes sociais, } \\
\text { estupro pela } \\
\text { ótica de quem } \\
\text { foi vítima aos } 15 \\
\text { e } 25\end{array}$ & CG News & Năo & Năo houve referência. \\
\hline $31 / 05$ & $\begin{array}{l}\text { Noticia/ } \\
\text { Informativo }\end{array}$ & $\begin{array}{l}\text { Governo anun- } \\
\text { cia criaçâo de } \\
\text { núcleo de com- } \\
\text { bate à violência } \\
\text { contra mulher }\end{array}$ & $\begin{array}{l}\text { Agência } \\
\text { Brasil }\end{array}$ & Năo & $\begin{array}{l}\text { Uso adequado de terminologias; } \\
\text { contextualizaçâo conceitual sobre } \\
\text { relaçôes de gênero e poder, ma- } \\
\text { chismo; fala de políticas públicas } \\
\text { para promoçăo dos Direitos Huma- } \\
\text { nos e enfrentamento à violência } \\
\text { sexual; apresenta dados de violên- } \\
\text { cia contra mulher. }\end{array}$ \\
\hline
\end{tabular}

Em linhas gerais, os dados levantados na tabela mostram preocupaçăo com o crime; foram utilizadas terminologias adequadas de modo a preservar a vítima, evitando e condenando a culpabilizaçăo. Foram feitas contextualizaçôes conceituais sobre relaçôes de gênero e poder, machismo e cultura do estupro. Mas apenas uma publicaçâo tentou fazer uma aproximaçăo com a realidade local, utilizando como fontes mulheres campo-grandenses que falaram sobre seus medos e angústias. Ainda assim, bem como nas outras publicaçôes disponibilizadas no portal, năo foi feita nenhuma abordagem acerca dos dados de violência sexual cometida contra mulheres em Campo Grande, nem dos serviços disponíveis para atendimento de vítimas, mesmo diante do fato da capital sul-mato-grossense ter sido a primeira cidade brasileira a receber a Casa da Mulher Brasileira9, em funçâo dos altos índices de violência de gênero.

Em nenhuma das publicaçóes houve mençăo aos aspectos de violaçăo, a partir do que preconiza o Estatuto da Criança e do Adolescente. Nâo foram feitas referências ao artigo 15, que garante a prioridade absoluta da adolescente no respeito à liberdade e dignidade, nem do artigo 18, que especifica que o direito ao respeito consiste na

9 A Casa da Mulher Brasileira integra no mesmo espaço serviços especializados para os mais diversos tipos de violência contra as mulheres, facilitando o acesso aos serviços especializados para garantir condiçóes de enfrentamento da violência. 
inviolabilidade da integridade física, psíquica e moral, abrangendo a preservaçăo da imagem e da identidade da adolescente.

Observamos que, embora as publicaçôes tenham contextualizado e provocado certa reflexáo sobre a cultura do estupro, as notícias próprias do site foram pontuais náo desenvolveram aspectos normativos importantes para a ampla compreensáo do problema e qualificaçăo do debate público.

\section{CONSIDERAÇÕES POSSÍVEIS}

Constatamos pela avaliaçâo exploratória realizada no período de 30 dias que o tema estupro/violência contra a mulher ganhou notoriedade, impulsionado pelo caso de estupro coletivo no Rio de Janeiro que pautou as redes sociais e consequentemente os veículos de comunicaçăo, estabelecendo outra lógica de agendamento que advém da mobilizaçâo da sociedade e dos espaços virtuais que proporcionam a difusâo da informaçăo. Isso fica claro pela maneira episódica que o tema estupro é tratado no ciberjornal. As publicaçôes se concentram especificamente após a divulgaçăo do caso, sendo mais da metade delas (5) nos dois dias seguintes. Antes e depois do período de análise o tema esteve restrito a casos isolados de violaçăo de direitos, e enquadrado como plantăo policial.

A centralidade das redes sociais no agendamento (e dos grupos que ali se mobilizaram) foi comprovada também pelas próprias pautas que citam e fazem constante referência, especialmente, à rede social Facebook, explicitadas títulos: "No tribunal das redes sociais, estupro pela ótica de quem foi vítima aos 15 e 25", e a nota "Nada revoltou mais que estupro coletivo..." foi anunciada na fanpage como "assuntos que mais bombaram nas redes sociais nesta semana". A primeira publicaçăo sobre o caso, que denominamos como reportagem, "Em crimes que envolvem estupro, precisamos expor o problema e năo a vítima", segue um roteiro que foge as regras da informaçáo propriamente dita; é construída em primeira pessoa e pautada por relatos de militantes no Facebook, todas da cidade de Campo Grande. As fontes săo analisadas e citadas a partir das suas publicaçôes na rede, permeada pela interpretaçâo e opiniâo da repórter. Foi a publicaçăo com maior engajamento na fanpage do cibejornal no período (com mais de 1750 curtidas, 374 compartilhamentos e 100 comentários). Identificamos no período justamente uma tendência de priorizar depoimentos pessoais (mais saliente nos artigos), o que sinaliza para um jornalismo mais autoral, mais impositivo, mas que peca por negligenciar a prestaçáo de serviço.

Por um lado, o Campo Grande News deu voz às mulheres que se sentiram encorajadas a emitir sua opiniăo, como na reportagem acima citada, e permitiu a exposiçấo de experiências particulares, caso do artigo "No tribunal das redes sociais, estupro pela ótica de quem foi vítima aos 15 e 25". Por outro, trouxe poucas informaçôes propriamente sobre o caso do estupro coletivo (com exceçăo das reproduçóes da Agência Brasil), acabou por repetir as mesmas informaçôes sobre o crime em intertítulos vagos e nâo conseguiu contextualizar com a situaçăo local de violência, nem em pautas pertinentes como aquelas sobre o posicionamento de instituiçôes e autoridades locais - "Líder feminina no Congresso, Simone se diz chocada com estupro coletivo no RJ" e "OAB classifica como 'inaceitável' e divulga nota em repúdio a estupro coletivo". 
Os textos também nâo colocaram em discussăo o fato de a vitima ser adolescente e tampouco trouxeram informaçôes sobre a rede de atendimento à mulher existente na capital e as legislaçôes vigentes.

Concluímos, portanto, ainda que preliminarmente e na leitura do ciberespaço, que o Campo Grande News oportunizou o acesso ao tema estupro aos seus diferentes públicos. Sobretudo, o portal foi agendado pela demanda das redes sociais nâo só no assunto abordado, mas na própria linguagem utilizada: ainda que questionadora, bastante autoral, efêmera e com pouco respaldo informativo. 


\section{REFERÊNCIAS}

ANDI. Concurso Tim Lopes: um estudo de caso sobre a atuaçâo da imprensa no enfrentamento da violência sexual contra crianças e adolescentes. Brasília, 2006.

ANDI. Direitos Humanos na imprensa brasileira: uma radiografia. [s/d]. Disponível em: http://www.dhnet.org.br/educar/1 congresso/008 021 congresso veet vivarta.pdf. Acesso em 20 de junho de 2016.

BARROS FILHO, Clóvis de. Ética na Comunicação - da informação ao receptor. Sâo Paulo: Moderna, 2001.

BRASIL. Estatuto da Criança e do Adolescente. Lei Federal n 8.069. Brasília: Congresso Nacional, 1990.

FÓRUM BRASILEIRO DE SEGURANÇA PÚBLICA. Anuário brasileiro de segurança pública. São Paulo: 2017, ano 11, 107p. Relatório. Disponível em: <http://www.forumseguranca. org.br/wp-content/uploads/2017/12/ANUARIO_11_2017.pdf>. Acesso: 2 abr. 2018.

LIPPMANN, Walter. Opiniāo pública. 2. ed. Petrópolis: Vozes, 2010.

MELO, José Marques. A opiniāo do jornalismo brasileiro.2.ed. Petrópolis: Vozes, 1994.

MORA, Gabriela Goulart. O concurso Tim Lopes de Investigaçāo Jornalística como estratégia de agendamento da violência sexual contra crianças e adolescentes na imprensa brasileira. Brasília: UnB/ Faculdade de Comunicaçāo, 2008.

PADILHA, Sônia. Os valores-notícia no webjornalismo. In: Jornalismo convergente: reflexōes, apropriaçōes, experiências. LONGHI, Raquel; D' ANDRÉIA, Carlos (Orgs). Florianópolis: Insular, 2012.

PIOVESAN, Flávia. Direitos Humanos e o Direito Constitucional internacional. $8^{a}$ ed. São Paulo: Saraiva, 2007.

SILVA, Gislene. Para pensar critérios de noticiabilidade. Revista Estudos em Jornalismo e Mídia. Universidade Federal de Santa Catarina, v. 2, n. 1, 2005.

SILVA, Luiz Martins da. Sociedade, esfera pública e agendamento. In Metodologia de pesquisa em jornalismo. BENETTI, Marcia; LAGO, Cláudia (Orgs.). 3. ed. Petrópolis: Vozes, 2010.

SODRÉ, Muniz. A narraçāo do fato: notas para uma teoria do acontecimento. Petrópolis: Vozes, 2009.

TRAQUINA, Nelson. O Poder do Jornalismo: análise e textos da teoria do agendamento. Coimbra: Minerva, 2000.

VIDIGAL, Edson. O papel do jornalismo investigativo. 2002. Disponível em:http://bdjur.stj.jus. br/jspui/bitstream/2011/16855/Imprensa Investigativa.pdf. Data de acesso: 13 abril de 2016.

RECEBIDO EM: 18/07/2018

APROVADO EM: 10/11/2018 